To the Editors:

\title{
A descriptive study on self-poisoning in Ampara
}

Ceylon Medical Journal 2012; 57: 50

\section{Introduction}

Digamadulla district of the Eastern province of Sri Lanka has two health regions, Ampara, the area investigated in this study, and Kalmunai, which is predominantly Muslim and Tamil in ethnicity distribution. The total population of Ampara health region is 226,676 and over 99\% of them were Sinhala in 2007 [1]. Epidemiology of self-harm in Ampara health region has not been studied before.

In our study all hospital admissions after selfpoisoning during a period of three months (from June to September 2009) were retrospectively studied. All 10 hospitals in Ampara area were included: General Hospital - Ampara, Base Hospitals - Dehiattakandiya and Maha Oya and Rural Hospitals - Damana, Thottama, Padiyathalawa, Senarathpura, Panama, Wadinagala and Lahugala. Data obtained from admission registers were verified by tracing actual patient records.

There were 230 admissions in this period, i.e. an incidence rate of 406 self-poisoning per 100,000 per year, assuming all cases admitted to a hospital. This rate is apparently higher than previously reported figures in two concurrent studies done in Anuradhapura (315) and Hambantota (363) in 2002 [2, 3]. The incidence rate of selfpoisoning in our study is 20.7 times of the national suicide rate for 2010 (19.6 per 100,000 per year) [4].

The majority of patients were young, female and Sinhala. More than two thirds (70.4\%) were found to be below the age of 30 and only $7.4 \%$ were above the age of 49. 75.2\% were females. However, females significantly outnumbered males only in the $15-19$ age group $(2=6.12$, $\mathrm{p}=0.013$ ) but not thereafter. Most (92.6\%), were Sinhala while $5.7 \%$ were Tamil, and $1.7 \%$ were Muslims. Ethnic breakdown may not be meaningful due to transfers from other areas, especially Kalmunai health region for the want of ICU beds.

The two leading substances of poisoning were pesticides, which was 39 (17.0\%) out of 230 admissions. Other common and significant agents were paracetamol
(29 admissions, 12.6\%), weedicides (29 admissions, 12.6\%), yellow oleander (19 admissions, 8.3\%) and kerosene oil (18 admissions, 7.8\%).

When broader groups were considered, all agrochemicals and all medications were found to have approximately equal proportions, i.e. $29.6 \%$ and $29.1 \%$, with a cumulative figure of $58.7 \%$. According to our study pesticide use in Ampara (17.0\%) was comparable to that of Colombo (20.9\%) in 2007, but much less than that in Anuradhapura (55.3\%) in 2002 [2,5]. When all medications were considered as a means of selfpoisoning, it was high in Ampara (29.1\%) compared to its counterpart reported in Anuradhapura in 2002 (12.0\%) [2]. However, it appears that paracetamol was less commonly used in Ampara in 2009 than in Colombo (12.6\% vs. 51.8\%) in 2007 [5].

The major limitations of our study were its retrospective methodology and shorter period of study time.

\section{References}

1. Basic population information on Ampara district Preliminary Report. Department of Census and Statistics, Sri Lanka. 2007. Available from: http://www.statistics.gov.lk Accessed on 18 Jun 2011.

2. Eddleston M, Sudarshan $\mathrm{K}$, Senthilkumaran $\mathrm{M}$, et al. Patterns of hospital transfer for self poisoned patients in rural Sri Lanka: implications for estimating the incidence of self-poisoning in the developing world. Bulletin of the World Health Organization 2006; 84: 276-82.

3. Manuel C, Gunnell DJ, van der Hoek W, et al. Self-poisoning in rural Sri Lanka: small-area variations in incidence. $B M C$ Public Health 2008; 8: 26-34.

4. Crime Trends. Sri Lanka Police Service. 2010. Available from: http://www.police.lk/divisions/crime/mode_suicide_ 2010_first_6months.htm. Accessed on 18 Jun 2011.

5. De Silva V, Ratnayake A. Increased use of medicinal drugs in self-harm in urban areas in Sri Lanka. Archives of Suicide Research 2008; 12: 366-9.

\section{Rajasuriya ${ }^{1}$, M A I Asanthi², N Ranaweera $^{3}$}

${ }^{1}$ Department of Psychological Medicine, Faculty of Medicine, University of Colombo, Sri Lanka, ${ }^{2}$ Medical Research Institute, Colombo, Sri Lanka, ${ }^{3}$ Mental Health Focal Point, Office of Regional Director of Health Services, Ampara, Sri Lanka.

Correspondence: MR, e-mail: <Mahesh.Rajasuriya@gmail.com>. Received 6 July and revised version accepted 13 October 2011. Competing interests: none declared. 